\title{
Estela, a psicose, um caminho entre pedras
}

\author{
SÉRGIO DE GOUVÊA FRANCO (*)
}

\begin{abstract}
«A humildade e a confiança são bases seguras para o autoconhecimento e o crescimento pessoal. Não se deve se afastar destes valores: eles são o caminho que permite evitar a humilhação e a soberba.»
\end{abstract}

\section{ESTELA, ESTELA, ESTELA}

O atendimento mobiliza o analista como poucos: há um desafio técnico, há um mistério à frente. Trata-se de um atendimento no limite, na fronteira; em alguns casos opera-se aquém da psicose, neste opera-se para além. Há um fascínio pelo tratamento, ainda que a remuneração percebida seja menor do que a desejada. Aquilo que amedronta faz crescer. A recusa do caso teria impedido o crescimento do analista. A aceitação renova a vida, como um desafio adequadamente dimensionado.

O sofrimento da paciente é grande. A crise de angústia que a trás ao consultório antes a levará a um hospital geral, durante férias com a família no litoral norte de São Paulo. Bonita, inteligente, jovem, último ano de um curso na Universidade de São Paulo. À primeira vista, a família seria bem estruturada. O pai engenheiro, a mãe é artista plás-

(*) Psicanalista. Universidade Paulista. tica, a irmã mais velha já morou na Europa e atua no mercado financeiro. A investigação mais cuidadosa mostra, entretanto, que naquilo que $\mathrm{R}$. D. Laing chamou de “a política familiar”, Estela perde feio (Laing, 1971). Nos jogos de poder é humilhada, a feminilidade ferida, a vida fortemente machucada. Não apenas ela, a família toda sofre dissimuladamente os feitos destruidores da loucura.

Elementos de paranóia, elementos de esquizofrenia. É possível identificar seu medo, em seu modo de falar, em seu jeito de trazer o material. Assustada, qualquer barulho a faz estremecer. Parece sempre invadida, sem pele psíquica suficiente, sem unidade, cindida, sem proteção na fronteira (Anzieu, 1989). Seus gestos (no início) são truncados, sem harmonia, sem beleza: tiques. Vive com medo de todos em sua escola. Teme que alguém na sala de espera escute o que está dizendo. Palavras construídas e alteração radical na entonação das palavras: o afastamento da comunidade dos falantes: palavras feitas e refeitas, segundo os critérios da condensação e deslocamento. A presença do inconsciente se faz.

São perturbações importantes na imagem do próprio corpo, especialmente na boca e face e em toda região do ventre. É preciso notar que são partes constituintes do aparelho digestivo: a boca e o estômago. Perturbações na oralidade que aqui se manifestam? Pensa que sua barriga vai crescer. Chega a bater na barriga para que esta não "cresça”. Desconfia que seja possível ver sua barriga enorme e rebelde através de um decote de casaco que não vai além da linha de seus peitos. Delírio. 
Em várias sessões toma os óculos escuros da bolsa para servir como espelho: precisa se certificar na imagem refletida na lente dos óculos que sua face não se desintegra. Sonha que não possui uma metade do corpo. Conta uma alucinação visual: teria visto um E.T., olhando para ela na cama. Mas ela avança: "fechei os olhos e ele desapareceu". Frente à sugestão de procurar um psiquiatra no início do atendimento, ela recusa terminantemente a idéia: não quer ser estigmatizada como louca.

São ataques violentos do supereu. Tudo o que faz, pensa e constrói é profundamente atacado. Tem pensamentos contraditórios que a atormentam. Cindida, não pode decidir. Pertencente a uma família cristã, ela se questiona se esta fazendo algo errado contra Deus, que a estaria punindo. Há esta experiência de estar sem rumo, sem norte, sem parâmetro. Há uma fruição constante, sem referências fixas. O psicótico - como se diz - não tem para onde retornar, não tem casa. Confusão.

\section{A PSICOSE}

A etimologia da palavra psicose não ajuda muito, trata-se de um derivado verbal do conhecido grego $\psi v \chi \eta$, que quer dizer alma, vida, indivíduo, pessoa. Thayer diz: «é quase o conceito moderno do ego» (Taylor, 1978). A terminação de psicose indica no grego “animar, dar vida”. Psicose seria assim algo como a vida egoíca. O sentido psiquiátrico é relativamente recente, parece que ele foi introduzido por von Feuchtersleben decano da Faculdade de Medicina de Viena - em 1845. Ele queria indicar um estado generalizado de perda de juízo de realidade. Durante o século XIX se difundiu a noção de psicose, basicamente na literatura psiquiátrica de língua alemã, para designar as enfermidades mentais em geral, vale dizer a loucura (Galo, 2001). Se a pesquisa etimológica não é importante, a pesquisa na história da psiquiatria é: tal pesquisa foge, no entanto, aos propósitos deste artigo.

Com o aparecimento da psicanálise várias noções sobre a psicose se estabelecem. Sabemos que o trabalho clínico de Freud se centrou fundamentalmente nas neuroses. A investigação a respeito das psicoses ficou em grande medida entregue aos seus discípulos e continuadores. Grande parte do que Freud pensou e escreveu sobre psicose se deu em meio ao seu contacto com Jung. A dupla Jung e Bleuler representava o melhor da psiquiatria do início do século XX, com uma ênfase dinâmica que os aproximava da psicanálise. Freud preferiu pensar o domínio da psicose sob a categoria da paranóia em vez da esquizofrenia. Sob a influência da amizade com Jung é que escreve Schreber em 1911, discutindo as questões do recalque das pulsões homossexuais e da projeção na paranóia. O que procura é estabelecer uma etiologia e funcionamento psíquico da psicose, desvalorizando o fundamento orgânico (Freud, 1911). Devemos reconhecer que Freud tinha considerado os mecanismos de projeção na psicose desde os seus trabalhos no fim do século XIX. Assevera desde esta época que os sintomas delirantes devem ser vistos como tendo sentido e nexo para os pacientes. Mas o trabalho mais importante de Freud sobre a psicose é certamente o seu estudo do relato autobiográfico de Schreber.

O que está ausente no texto de Schreber é a discussão da psicose em torno do tema do narcisismo. Este tema será abordado em 1914, portanto três anos mais tarde, quando a psicose passa a ser vista como uma retração da libido ao eu, que é retirada de pessoas e coisas do mundo externo (Freud, 1914). A megalomania, por exemplo, é o resultado deste retraimento libidinal. O que fica claro é que na psicose a sustentação psíquica do sujeito depende de um outro como um duplo, como um arrimo de sua integridade. Uma perturbação neste apoio pode desencadear a degradação psicótica: o eu não suporta a alteridade. O delírio de grandeza ou o delírio de perseguição são formas compensatórias do desmantelamento do eu. Nos textos posteriores Neurose e psicose e A perda da realidade na neurose e psicose publicados em 1924, Freud afirma que na psicose há uma problemática entre o eu e o mundo externo. $\mathrm{O}$ eu cria um mundo interno e externo, devido a uma frustração intolerável, que substitui a realidade. A maioria dos sintomas manifestos, especialmente as construções delirantes, devem ser entendidos como tentativas secundárias de restauração do laço objetal (Freud, 1924 “Neurose e Psicose” e Freud, 1924 “A Perda...”).

Quase encerrando a sua obra, em 1937, Freud destaca a importância da construção em análise (Freud, 1937). É que Freud descobre que nem sempre se trata de encontrar um material recalcado, que deve ser recordado. Os delírios na psicose são 
comparados ao trabalho de construção: são tentativas de explicação e cura. Compreende-se assim que em Freud, o delírio tem uma função organizadora na psicose. Compreende-se também que todo delírio tem um fragmento de verdade.

\section{O PARADIGMA WINNICOTIANO}

Winnicott simultaneamente se aproxima e se afasta da psicanálise freudiana. Em busca de análise, procurou em 1923 Ernest Jones. Foi Jones quem o colocou em contacto com James Strachey, com que fez análise por dez anos. Quem começa com Jones e Strachey, começa com Freud. Ao fim de dez anos, Strachey encaminha Winnicott a Melaine Klein. Strachey entende que se Winnicott está preocupado em aplicar a psicanálise às crianças, deve travar contacto estreito com ela. Winnicott toma Klein como supervisora e se forma com ela, mas vai muito além dela. Todas as formulações sobre a criatividade, sobre fenômenos e objetos transicionais, por exemplo, permanecem estranhas ao campo kleiniano. Winnicott parece ser o primeiro analista contemporâneo sem escola. A herança freudiana e kleiniana estão sujeitas a constantes reformulações e mudanças, a partir de uma experiência clínica muito diferente das experiências destes seus dois mestres. Nunca constituiu um grupo ao redor de suas verdades, permitindo que os analistas que se aproximavam ficassem livres para se apropriar do que quisessem. Foi Masud Khan, a partir da segunda metade do século XX, que passou a divulgar a obra e o pensamento de Winnicott. Em Winnicott, podemos dizer, a tradição e a descoberta estão em articulação. Do saber freudiano ao saber kleiniano, Winnicott produziu uma psicanálise própria.

Uma das mudanças fundamentais que interessa aqui destacar é que em Freud a neurose tem um valor de referência, é um ponto de partida para as formulações sobre o funcionamento psíquico. Em Winnicott, são os casos fronteiriços e a psicose que fornecem os elementos para suas transformadoras contribuições. Winnicott está atento ao vazio da experiência dos bordelines. Ele se dá conta de que o acontece antes é o que importa. Ou, colocando de outra maneira, o que importa é o que não aconteceu antes, impedindo a integração que leva a formação da personalidade. Não que Freud esteja errado, pensa ele, apenas toma como dado algo que nem sempre ocorre. Nos primórdios, o ego está por se constituir e a integração é uma possibilidade que dependerá de muitos fatores e pode não se dar.

Em Freud, os sentimentos de culpa, de perseguição e de angústia são de origem no complexo de Édipo, ou seja, em uma relação triangular: mãe, pai, filho. Klein observou, entretanto, estes sentimentos em momentos muito anteriores, em fases pré-edípicas, nas relações iniciais mãe/bebê. Tais observações criaram uma questão à metapsicologia freudiana. Com vistas a manter a centralidade do complexo de Édipo é que Klein postula um Édipo precoce. Uma dificuldade é que Freud via nos momentos iniciais uma relação dual e não triática. Klein resolve o impasse imaginando que crianças de ambos os sexos mantêm com a mãe, desde o início, uma relação a três. Para ela a criança possui um saber inato sobre o estatuto triangular dos relacionamentos.

Winnicott considerava Klein uma grande clínica; quando começou a se relacionar com ela, ficou surpreso que ela já soubesse sobre as crianças aquilo que ele ia aos poucos aprendendo em sua própria clínica. Mas depois de um tempo estudando com ela, Winnicott conclui que o complexo de Édipo precoce de Klein, ainda que fosse uma solução engenhosa, não correspondia às suas vivências e problemas clínicos. Fica convencido que existem temas iniciais na vida humana que não podem ser tratados com os elementos da concepção edipiana: são angústias primordiais que falam de ameaças à própria existência humana: medos de aniquilamento, de entrar em um estado de não-integração, de perder o contacto com a realidade, de desorientação espacial e de experiências de estar desalojado do próprio corpo. Uma característica básica destas angústias todas é que elas se dão antes que exista um indivíduo em condições de experienciá-las. Portanto, elas não podem ser entendidas em termos dos conflitos gerados nas relações edipianas.

Winnicott pensa que a condição inicial não é tanto de um Édipo potencial, mas a de um ser frágil, finito, que precisa de um outro humano para continuar existindo: as primeiras relações não são do tipo objetal. O bebê precisa da mãe e só ela pode, por meio de seus cuidados, garantir que surja nele a confiança em si próprio e no mundo. Para Winnicott não se trata de inveja ou ciúme de algum objeto inicial, não o seio, nem a própria 
mãe. O bebê não pode nestes momentos iniciais distinguir seu eu daquilo que é “não eu”. Não existe um objeto interno ou externo, bom ou mau. A relação de dependência do bebê para com sua mãe não é uma relação a três. Nem mesmo uma relação a dois. Talvez seja importante esclarecer: no início o bebê enquanto tal não existe. Não há uma distinção entre o interno e o externo, entre o próprio e não próprio. Nas condições do início, o bebê tem necessidades e problemas que tem a ver com as garantias de sua integração no tempo e espaço, até que possa criar a distinção da realidade interna e externa, das coisas e de si mesmo.

Estas angústias, que Winnicott chamou de "impensáveis”, têm origem em uma falha ambiental específica. Quando a mãe não pode, por qualquer razão, assegurar a evolução do humano rumo a um certo grau de integração, angústias impensáveis aparecem. Estas angústias têm uma importância clínica fundamental: estão profundamente relacionadas à etiologia e tratamento das psicoses. Nesta forma de ver, os problemas edípicos só se tornam centrais se um certo grau de saúde psíquica for atingido. Se for, pensa Winnicott, as formulações metapsicológicas e clínicas de Freud são inteiramente aplicáveis. Caso haja interrupções e mesmo colapsos da integração progressiva inicial, criando condições para o aparecimento da psicose, a renovação da técnica é fundamental.

\section{A CONSTRUÇÃO DE UM CASO}

Pierre Fedida e François Villa organizaram em 1999 uma coletânea sobre a natureza do caso clínico: "Le cas en controverse” (D’Agord, 2001, pp. 7-11). As reflexões veiculadas nesta coletânea e as que a partir daí se multiplicaram, produzidas por vários autores, em várias partes do mundo, têm o condão de desmistificar uma visão ingênua do caso clínico e relançá-lo em uma perspectiva epistemológica mais ampla. Ainda que o caso seja construído a partir de uma história pessoal, ele não é um testemunho positivista. O que fica em evidência no caso não é tanto a pessoa do paciente, quanto o tratamento do paciente. Tratase de uma reconstrução de eventos clínicos que surge de dentro de um quadro de referência, onde o próprio analista está inserido. Entre a dimensão fenomenológica, sintomatológica e a perspectiva diagnóstica, há um esforço que busca organizar, interpretar e relançar o acontecido no tratamento em um contexto metapsicológico. Colocando de outro modo: a construção do caso depende da situação analítica, ou seja, da transferência e do trabalho clínico.

A importância do caso, como ensina Fedida, tem a ver com sua dimensão de pesquisa, de investigação, de expansão do pensar clínico e metapsicológico: «o caso é uma teoria em germen» (D’Agord, 2001, p. 12). Trata-se de um trabalho que procura dar conta do que vai acontecendo na clínica, para além do que se sabe e para além do que é primeiramente consciente. Neste sentido a construção do caso tem uma dimensão de prospecção, de avanço em uma região ainda escura. Não há interesse em se repetir o conhecido. O vivido na clínica está sempre exigindo muito mais do que se sabe. Para se dar conta daquilo que não se tem domínio é precisa se lançar, construindo aquilo que ainda não existe. Neste processo de reconstrução do caso, a partir das experiências clínicas, a participação do analista tem um largo papel. Não falamos de arbitrariedades ou elucubrações interpretativas, mas de um trabalho fiel e cuidadoso, consciente de que o caso sem o trabalho do analista não existe.

A epistemologia psicanalítica é clínica, precisamos repetir e valorizar em tempos em que o método quantitativo freqüentemente é apresentado como o único que faz jus ao título de científico. $\mathrm{O}$ rigor quantitativo tem valor e lugar: ele segue sendo um outro do método clínico, a ser considerado. Todavia, segue o engano, sustentado por relações institucionais com poder, de pensar que o subjetivo possa ser recolhido dispensado a concorrência do próprio subjetivo, captado apenas por métodos objetivantes. Na construção de um caso não há cisão pesquisador/pesquisado, não há uma observação de fora da cena - aí a sua força. A clínica da escuta e não a clínica objetivante é que está em condições de sustentar a subjetividade envolvida. Ela é que traz à tona elementos insuspeitos e inconscientes ao par paciente/analista. Na escuta o analista produz, tem uma atividade associativa e mesmo especulativa. É na transferência que o caso é construído. Ao contrário de fraqueza metodológica, trata-se de uma libertação tanto do narcisismo do paciente e do analista, quanto de um enfoque que não enxerga aquilo que não pode ser pesado ou medido. Caon afir- 
ma: «não parece possível ao analisante escrever seu retrato metapsicológico próprio» (Caon, 2001, p. 43). A construção do caso é uma contribuição científica primeiramente ao paciente em toda a sua riqueza e complexidade, que recebe como oferta uma narrativa inédita com que pode se identificar, mas é também uma contribuição à pesquisa e elaboração metapsicológica, fazendo avançar enigmas e mistérios que aparecem não em outro lugar que não na própria clínica e na própria vida.

$\mathrm{O}$ que temos aqui mais do que um estudo de caso é a construção do caso Estela, onde o drama pessoal da paciente é acompanhado e escutado pelo analista, em busca de sentido e cura. Toda construção do caso é feita dentro de hipóteses metapsicológicas, a presente construção não é diferente. Toda construção de caso visa um grupo que recebe e aprecia o trabalho do psicanalista/pesquisador, a presente construção não é diferente. A construção de caso renova a clínica do analista e renova o seu modo de pensar. Como escrevem Ana Moura e Isac Nikos sobre a pesquisa psicanalítica com construção de caso: «eis aí a principal essência do que se chama pesquisa psicanalítica: promover uma abertura de sentidos para os dados em que o pesquisador está debruçado» (Moura \& Nikos, 2001, p. 75). Não é outro o propósito do presente trabalho que não buscar sentido e cura para o paciente, construindo e elaborando aspectos clínicos e metapsicológicos com abertura de sentidos para os dados sobre os quais se está debruçado.

\section{ESTELA E A PSICOSE}

Estela aparece ao analista como frágil em suas relações familiares. A psicose começa a ser pensada junto com o relacionamento inicial mãe e filha. Frágil ela própria, a mãe poderia não ter sido capaz de impedir as invasões e descontinuidades de proteção a uma personalidade que ainda não se constituía. Parece ser necessária agora a recuperação da técnica ativa: o analista teria que se adaptar às necessidades da paciente onde a mãe falhou. Estela se identifica com a mãe frágil que a desprotegia. Não consegue reconhecer a violência dos constantes ataques do pai agressivo. Ele a chama de "puta”, mas Estela não consegue reconhecer a violência, ainda que todo o seu interior “derreta como manteiga”, de horror. Não apenas não sabe reconhecer a violência quando a experimenta, como tampouco sabe reconhecer o bem-estar que tão raro vivencia.

Esmagada pelo pai, sente que não pode colocar em questão a sua violência. Teme desestabilizar a frágil força paterna e possivelmente toda família. O forte e violento pai lhe parece finalmente fraco: não pode sustentar suas necessidades e fraquezas. Diz que a mãe tem visões de "velhinhos" que à noite a vem assustar: a psicose de Estela poderia ter nascido de uma suposta psicose materna. O corpo se move desconexo, como se nunca tivesse sido segurado adequadamente quando bebê. Que recursos uma mãe teria, sendo ela mesma psicótica, para segurar seu bebê e produzir nele unidade e segurança? Parece, usando elementos da linguagem winnicottina, que não houve continuidade na formação do seu ser e experiência. Ninguém a pode sustentar: não confia - não financeira, nem emocionalmente.

Tudo perturba seu débil contorno corporal/egoíco. Elementos de sua sexualidade e agressividade não podem se expressar em casa. Seu sofrimento garante a homeostase familiar. Ela se funde em busca de sustentação. Estela está com medo, de todos, praticamente o tempo todo. Todos - teme vão machucá-la. Neste contexto terrorífico é que aparecem nela os tiques, a timidez, o medo, a loucura. A desintegração da imagem corporal aponta para a gravidade de seu estado. Tudo reforça a idéia de que perturbações fundamentais ocorreram no relacionamento primeiro entre Estela bebe e sua mãe.

Estela evoca pela sua vida e sofrimento uma contundente frase da sofrida e talentosa artista plástica mexicana; Frida Khalo registrou em seu diário: «yo soy la desintegracion» (Outeral, 2002, p. 22). O mesmo poderia ser aplicado à vida e experiência de Estela.

\section{PSICOSE E CUIDADOS FUNDAMENTAIS}

No modo de compreender de Winnicott, as bases para a saúde mental são lançadas na primeira infância, por uma mãe dedicada ao seu filho. Sem esta ambientação favorável, o bebê sofre. Winnicott vê uma linha de continuidade no humano, da concepção à morte, de modo que «a criança é o pai do homem» (Winnicott, 1952, p. 306). Sem a experiência de uma construção psíquica paulati- 
na na infância, o adulto adoece. A saúde da criança e do adulto dependem, portanto, em importante medida da possibilidade da mãe de cuidar das necessidades de seu filho lactante. Estas necessidades no início são absolutas. Da mãe se espera uma dedicação imensa no começo da vida de seu filho. Winnicott gosta da palavra "devoção”, que uma vez despida de todo sentimentalismo, pode expressar o trabalho intenso da mãe no trato do seu filho. «A saúde mental é o resultado de um cuidado incessante que possibilita a continuidade do crescimento emocional» (ibid). Embora Winnicott reconheça a complexidade e as dimensões controvertidas da etiologia da psicose, ele vê nas perturbações neste período da lactância, anterior a formação de um ser psíquico integral, fator etiológico fundamental para tal psicopatologia.

A partir de suas observações de crianças e, sobretudo a partir de sua experiência de cuidado de adultos psicóticos ou neuróticos graves, em estados momentâneos ou permanentes de regressão, Winnicott intui que no início o individuo não é uma unidade. Sua vulnerabilidade a estados esquizóides e à franca esquizofrenia depende em grande medida do modo como este ser ainda não integralizado é exposto à realidade. Trata-se de um momento delicado, quando o bebê depende absolutamente de sua mãe. Um fracasso importante aí resulta organizações defensivas contra a confusão e a não integração. Se a mãe está em condições de fazer uma adaptação ativa e sensível às necessidades do seu bebê, este pode permanecer protegido do ambiente até quando queira. Finalmente o bebê faz um movimento espontâneo e digamos "toca" o ambiente, descobrindo e construindo um "não eu”. Se o ambiente, por outro lado, não se adaptar ao bebê e entrar no mundo psíquico do bebê por sua iniciativa, o bebê vive isto como uma invasão e se defende. A defesa é o isolamento, que visa readquirir uma sensação de continuidade e proteção.

Nesta situação de falha do ambiente (basicamente oferecido pela mãe ou por alguém que a substitui) surgem as distorções psicóticas. Após a intrusão do ambiente no mudo do bebê, segue o seu isolamento psíquico e o aparecimento de uma organização defensiva para repudiar a invasão. Para Winnicott, a técnica para tratar pacientes, que tiveram esta experiência na infância, deve incluir a atitude que não foi experimentada pelo bebê: uma adaptação ativa e sensível às suas necessidades psíquicas, proporcionada por uma grande plasticidade da parte do analista.

Nos momentos iniciais, há um grande potencial criativo no bebê surgido de sua intensa necessidade, que o coloca em uma verdadeira prontidão para a alucinação. A mãe sensível, profundamente identificada com o seu bebê, acaba oferecendo, no momento certo e no lugar certo, exatamente aquilo que o bebê está alucinando. É esta experiência de criar o que lhe está sendo oferecido, de encontrar aquilo que alucina, repetidas muitas vezes, que dá ao bebê a ilusão da onipotência e o faz se sentir amado, importante, seguro. No caso destas coisas não acontecerem satisfatoriamente, fruto de uma adaptação insatisfatória do ambiente, surge uma cisão básica, onde uma vida secreta se estabelece com pouco ou nenhum contato com a realidade. O resultado é uma vida artificial e falsa, finalmente vazia, fria, sem sentido, baseada em total submissão. Em casos mais graves, o caos se estabelece. De qualquer forma a ilusão não se constitui e não se desfaz completamente, levando na vida adulta o paciente exigir do seu entorno a aquiescência para construções mais ou menos delirantes.

Várias perturbações podem se dar a partir destas insuficiências iniciais. Uma delas seria o uso da inteligência para compensar a experiência da não integração. Neste caso aparece um intelectualismo artificial, um excesso, que visa compensar a ausência desta adaptação do ambiente nos primeiros momentos. Aparece uma hipertrofia dos processos intelectuais que parecem completamente divorciados do corpo e afetos. Uma outra experiência é a sensação que estes pacientes tem de não se sentirem alojados no próprio corpo. Esta sensação de desintegração ameaça terrivelmente o paciente, tornando o indivíduo um paranóico por qualquer causa. No desenvolvimento mais feliz, o mundo externo com seus perseguidores e invasões são neutralizados pela presença e atuação da mãe devota, que sustenta o bebê física e emocionalmente. Sem esta proteção o potencial paranóide se desenvolve. É para se defender das terríveis angústias deste estado paranóide que surge uma forte organização defensiva, desde a infância. Para escapar ao ataque paranoicamente esperado, o paciente evita a integração. 


\section{ASPECTOS CLÍNICOS E METAPSICOLÓGICOS DA REGRESSÃO}

Winnicott valoriza o tema da regressão na clínica de pacientes graves. Suportar a regressão do paciente é, para ele, mais do que um aspecto da técnica, ou do estilo pessoal do analista. Trata-se de propiciar condições de desenvolvimento de um processo iniciado e conduzido pelo inconsciente do paciente, com seu ritmo, recuos e complexidades. A técnica ativa é o modo possível de manter a abstinência com pacientes graves: o que exige muitíssimo do analista. É uma ativa adaptação às necessidades do paciente, que permite a este avançar, ou voltar rumo aos seus sofrimentos mais brutais. Dado a primariedade do modo como o paciente se liga, cabe ao analista uma postura que se aproxima a de uma mãe que segura o seu bebê. Quando o analista deixa que o processo seja conduzido pelo inconsciente do paciente, exatamente como faz no tratamento da neurose, podem surgir no analista, neste caso da psicose, sentimentos difíceis de manejar: seu inconsciente é profundamente mobilizado. É preciso estar certo das dificuldades. Constantemente o tratamento ultrapassa o analista, que outra vez precisa ver o que lhe escapa.

A regressão de que fala Winnicott, refere-se a um tipo específico de paciente, com falhas importantes no relacionamento inicial mãe/bebê. Se não for possível suportar a regressão nestes casos, a análise pode se centrar sobre uma construção social grandemente falsa, que não representa as dinâmicas mais profundas da personalidade. Este mundo interior profundo, marcado por angústias e medos impensáveis, pode permanecer soterrado, disfarçado por esta construção defensiva que se chama psicose. A regressão para Winnicott representa, portanto, um poderoso recurso da psique, uma corajosa tentativa de ir até o ponto onde as "angústias impensáveis" foram experimentadas. Um destino muito mais infeliz na psicose - aliás, uma ameaça sempre presente - seria simplesmente o caos, situação onde a capacidade de regressão fica completamente anulada.

Talvez este ponto mereça uma elucidação. Para Winnicott a regressão está ligada à idéia de que frente a perturbações iniciais graves, houve um congelamento da situação de falha, que gera tanta angústia. Há também uma esperança de que em situações mais favoráveis futuras, esta falha con- gelada possa ser descongelada e tratada. Veja que ele não está pensando primeiramente na regressão libidinal a pontos de fixação do investimento e suas fases. A regressão de que fala é, sobretudo a regressão a uma situação de dependência e se refere ao desenvolvimento do ego. Ele está falando de uma adaptação adequada do ambiente, ainda que tardia. Se for possível uma regressão à dependência, processos curativos podem ser suficientes para descongelar a situação de falha e o vínculo entre a psicose e a saúde ser revelado. Isto só se dá se um ambiente de confiança real se estabelece.

O modo de refletir de Winnicott sobre a psicose destaca sua sensação de insuficiência diante do paciente: «Fui obrigado a crescer enquanto pessoa no decorrer do tratamento, de um modo doloroso que eu teria tido prazer em evitar» - assevera falando de um atendimento de uma paciente grave (Winnicott, 1954, p. 378). É honesto para reconhecer os impedimentos ao avanço do tratamento que se apresentam nele mais do que no paciente:

«Particularmente, foi-me necessário aprender a examinar a minha própria técnica toda vez que surgiam dificuldades, e em todas as cerca de doze fases de resistência ocorridas ficou claro em seguida que a causa originava-se de algum fenômeno de contratransferência, tornando necessária uma auto-análise adicional do analista.» (ibidem)

Com estas observações pretende esclarecer o que pensa sobre o que seja realmente a abstinência e o não atendimento da demanda do paciente. A técnica ativa na psicose não pode ser confundida com um simples reasseguramento. Ele avalia o ponto assim:

«Formações reativas no comportamento do analista são prejudiciais não porque se fazem presentes na forma de reasseguramento e negação, mas porque representam elementos inconscientes reprimidos no analista que irão limitar sua capacidade de trabalho.» (Winnicott, 1954, p. 390)

\section{ESTELA, A PSICOSE, UM CAMINHO ENTRE AS PEDRAS}

O caminho é entre pedras: machuca os pés. Se 
fosse neurose, poder-se-ia falar em pés inchados de Édipo. O caminho entre pedras aponta, entre outras coisas, para os limites do analista. Ele não é onipotente, não enxerga tudo. Ele pode se irritar com o baixo valor pago pela sessão, ou com a experiência velada ou expressa de frustração do paciente com o tratamento. $\mathrm{O}$ caminho é entre pedras também para o paciente. $\mathrm{O}$ analista não está disponível no fim-de-semana e férias, o paciente sofre, atua e ataca. O vínculo parece frágil. O paciente expressa intenção de interromper o tratamento, o analista se inquieta. São afetos complexos, a cisão está presente. A paciente quer se aproximar e quer se afastar, ao mesmo tempo. O analista não é suficiente. Será suficientemente bom?

Entre pedras, um caminho. A estabilidade do atendimento permite à Estela as primeiras expressões no consultório de traços de sua sexualidade e agressividade, que mal podem se constituir em família. Toma a iniciativa e vai para o divã. O divã não apenas representa o acolhimento do analista, o divã é o acolhimento do analista, seus braços, suas palavras. Os tiques diminuem, a paciente melhora. Começa a namorar: meses de namoro, beijo é só "selinho", nada de língua. A língua que não pode entrar na boca! O terror da invasão, da penetração, do aniquilamento. Língua invasão, violação, estupro. Seu débil contorno corporal/egoíco não agüenta... Parece que só uma compreensão e acolhimento excepcionais, incluindo não apenas a necessidade de aproximação, mas a necessidade de separação, não apenas a satisfação, mas a frustração e o medo do tratamento, podem permitir a continuidade do tratamento. Talvez um dia o beijo não seja violência, a língua não seja estupro e terror de se perder no outro. $\mathrm{O}$ analista precisa estar consciente sempre que também pode ser um excesso para a paciente: não está sempre disponível, não é perfeito, cobra e encerra as sessões, diz uma palavra que a paciente não aceita. Entre as pedras e a psicose, Estela se anima e vai encontrando um caminho... Ela se funde; regride à dependência. Entre pedras se prenuncia movimentos de busca e de concretização.

\section{CONCLUSÃO}

A julgar por certos modelos propostos, certos modos de construir um caso, as perspectivas não são nada animadoras para Estela. Mas aqui as vicissitudes de um self dissociado não devem ser vistas como um castigo eterno. Refletindo sobre trabalho anterior de Jacques Lacan e o estádio do espelho, Winnicott pergunta: o que vê o bebê quando olha para o rosto da mãe? O bebê normalmente vê a si mesmo, responde. É preciso entender que este normalmente expressa esta qualidade de uma mãe capaz de se identificar e se adaptar ao seu bebê, uma adaptação no começo quase completa. O olhar da mãe não é sem desejo, não é desinteressado. Winnicott não sugere que este olhar devesse ser vazio para não ocorrerem às intrusões. O olhar com desejo de Winnicott talvez devesse ser comparado à "violência necessária” de Pierra Aulagnier, talvez. O desejo da mãe expressa algo com o que o bebê pode se comunicar. O olhar invasivo, ao contrário, é o que reflete o humor da mãe voltada para si, ou pior ainda, reflete as suas defesas diante da vida. A mãe que não reage ao bebê, cujo rosto é fixo, inflexível, acostuma o seu bebê a não ser visto, mesmo quando olha para o espelho mãe. As conseqüências são a formação de um conjunto de mecanismos de defesa e a psicose. Segundo André Green há o complexo da mãe morta, aquela que mesmo viva é incapaz de reagir ao seu filho, esta mãe morta para o seu bebê, gera ela mesma uma morte psíquica mais ou menos intensa no seu pequeno filho.

Há quem diga que Freud nunca abandonou completamente sua teoria da sedução. Na verdade, ele gradualmente a modificou e integrou com base na sexualidade infantil. Se assim for, os efeitos nocivos da sedução propugnados em Freud podem ser comparados a esta mãe que "morre" para o bebê, apenas usando-o, sem real capacidade de enxergá-lo e refleti-lo. Cabe ao analista pensar o lugar que ocupa no tratamento do psicótico, quando sem qualquer sentimentalismo, sem negação da agressividade - marca fundamental da experiência humana - sem sedução, posso ativamente sustentar o paciente em seus processos de regressão necessários, que finalmente possam leva-lo a não apenas sentir angústias impensáveis, mas recuperar desde dentro do processo o seu crescimento emocional, com vivência e manifestação autênticas de si mesmo. 


\section{BIBLIOGRAFIA}

Abram, J. (2000). A Linguagem de Winnicott - Dicionário de Palavras e Expressões Utilizadas por Donald $W$. Winnicott. Rio de Janeiro: Revinter.

Ab'Saber, T. A. M. (1996). Um jogo de Winnicott. Percurso - Revista de Psicanálise, 9 (17), 18-26.

Anzieu, D. (1989). O Eu-pele. São Paulo: Casa do Psicólogo.

Berlinck, M. T. et al. (2001). Esquizofrenia e miscigenação. Revista Latinoamericana de Psicopatologia Fundamental, 4 (4), 7-16.

Belinck, M. T. (2000). Psicopatologia Fundamental. São Paulo: Escuta.

Caon, J. L. (2000). Retrato, auto-retrato e construção metapsicológica de Serguéi Constantinovitch Pankejeff, o "Homem dos Lobos”. Pulsional - Revista de Psicanálise, 13-14 (140-141), 22-44.

Cartocci, L., \& Franco, M. de M. (1996). Winnicott: contribuições de uma clínica para a atualidade. Percurso - Revista de Psicanálise, 9 (17), 7-10.

D’Agord, M. (2000). Sobre a coletânea Le cas en controverse. Pulsional - Revista de Psicanálise, 13-14 (140-141), 7-11.

D’Agord, M. (2001). Uma construção de caso na aprendizagem. Pulsional - Revista de Psicanálise, 13-14 (140-141), 12-21.

Delouya, D. (1996). A pulsão “destrutividade” e o "pai” do self. O Acesso ao real em Winnicott. Percurso Revista de Psicanálise, 9 (17), 27-34.

Franchtengarten, J. (1996). A exploração das dificuldades. Uma proposta de leitura de Winnicott. Percurso - Revista de Psicanálise, 9 (17), 49-55.

Freud, S. (1911). Notas Psicanalíticas sobre um relato autobiográfico de um caso de paranóia. Rio de Janeiro: Imago, 1996.

Freud, S. (1914). Sobre o Narcisismo: Uma Introdução. Rio de Janeiro: Imago, 1996.

Freud, S. (1924). Neurose e Psicose. Rio de Janeiro: Imago, 1996.

Freud, S. (1924). A Perda da Realidade na Neurose e na Psicose. Rio de Janeiro: Imago, 1996.

Freud, S. (1937). Construções em Análise. Rio de Janeiro: Imago, 1996.

Galo, A. G. (2003). Acerca de la Transferencia en Pacientes Gravemente Perturbados. Desde la Perspectiva de Donald Winnicott. Site Winnicott.net, 2001. Uruguai. Acesso, novembro de 2003.

Gonçalves, C. S. (1996). Ódio e medo na Contratransferência. Percurso - Revista de Psicanálise, 9 (17), 35-40.

Greif, L. M. V. (2003). D. W. Winnicott's Clinicalt. Site Winnicott.net, 2001. Argentina. Acesso, novembro de 2003.

Gurfinkel, D. (1996). O carretel e o cordão. Percurso - Revista de Psicanálise, 9 (17), 56-68.
Hoppe, M. W. (2001). Do modelo narrativo à escritura do fato clínico: o drama do paciente e o caso do analista. Pulsional - Revista de Psicanálise, 13-14 (140-141), 56-62.

Laing, R. D. (1969). Self and Others. New York: Pantheon.

Laing, R. D. (1971). The Politics of the Family. London: Tavistock.

Laing, R. D. (1979). The Divided Self: An Existential Study in Sanity and Madness. London: Penguin.

Leite, E. B. P. (1996). Ressonâncias do objeto. O brincar e o espaço analítico: Fedida, Winnicott e o fortda. Percurso - Revista de Psicanálise, 9 (17), 91-100 .

Leite, S. (2003). O desejo de Freud e a questão da psicose no campo psicanalítico. Pulsional - Revista de Psicanálise, 16 (175), 33-47.

Loparic, Z. (1996). Winnicott: uma psicanálise não-edipiana. Percurso - Revista de Psicanálise, 9 (17), 41-47.

Moura, A., \& Nikos, I. (2001). Estudo de caso, construção do caso e ensaio metapsicológico: da clínica psicanalítica à pesquisa psicanalítica. Pulsional - Revista de Psicanálise, 13-14 (140-141), 69-76.

Mutchinick, D. (2003). Winnicot: Una clinica que leva su nombre. Site Winnicott.net, 2001. Argentina. Acesso, novembro de 2003.

Outeiral, J., \& Moura, L. (2002). Paixão e Criatividade. Estudos Psicanalíticos sobre Frida Khalo, Camille Claudel, Coco Chanel. Rio de Janeiro: Revinter.

Rodrigues da Silva Jr., M. (1996). O Manejo da Regressão na Situação Analítica - Apontamentos sobre a perspectiva winnicottiana. Percurso - Revista de Psicanálise, 9 (17), 15-17.

Romano, V. (2003). Algunas Notas Acerca de la teoria de Winnicott. Site Winnicott.net, 2001. Argentina. Acesso, novembro de 2003.

Rosa, S. S. (1996). A dissociação do self e suas implicações na educação. Percurso - Revista de Psicanálise, 9 (17), 75-83.

Safra, G. (1996). A vassoura e o divã. Percurso - Revista de Psicanálise, 9 (17), 69-74.

Souza, M. L. R. (1996). Considerações... Percurso - Revista de Psicanálise, 9 (17), 11-14.

Taylor, W. C. (1978). Dicionário do Grego, Vocabulário Grego-Português. Rio de Janeiro: Juerp.

Vilete, E. P. (1996). Amor e ódio na obra de Winnicott (Cria Cuervos). Percurso - Revista de Psicanálise, 9 (17), 85-90.

Winnicott, D. W. (1975). O Brincar \& a Realidade. Rio de Janeiro: Imago.

Winnicott, D. W. (1982). A Criança e o seu Mundo. Rio de Janeiro: LTC Editora.

Winnicott, D. W. (1983). O Ambiente e os Processos de Maturação. Estudos sobre a Teoria do Desenvolvimento Emocional. Porto Alegre: Artmed.

Winnicott, D. W. (1990). Natureza Humana. Rio de Janeiro: Imago.

Winnicott, D. W. (1996). Os Bebês e suas Mães. São Paulo: Martins Fontes. 
Winnicott, D. W. (1999). Tudo Começa em Casa. São Paulo: Martins Fontes.

Winnicott, D. W. (2000). A Defesa Maníaca (1935). In Da pediatria à Psicanálise - Obras Escolhidas. Rio de Janeiro: Imago.

Winnicott, D. W. (2000). Desenvolvimento Emocional Primitivo (1945). In Da pediatria à Psicanálise Obras Escolhidas. Rio de Janeiro: Imago.

Winnicott, D. W. (2000). Pediatria e Psiquiatria (1948). In Da pediatria à Psicanálise - Obras Escolhidas. Rio de Janeiro: Imago.

Winnicott, D. W. (2000). Memórias do Nascimento, Trauma do Nascimento e Ansiedade (1949). In Da pediatria à Psicanálise - Obras Escolhidas. Rio de Janeiro: Imago.

Winnicott, D. W. (2000). O Ódio na Contratransferência (1947). In Da pediatria à Psicanálise - Obras Escolhidas. Rio de Janeiro: Imago.

Winnicott, D. W. (2000). A Agressividade em Relação ao Desenvolvimento Emocional (1950). In Da pediatria à Psicanálise - Obras Escolhidas. Rio de Janeiro: Imago.

Winnicott, D. W. (2000). Psicoses e Cuidados Maternos (1952). In Da pediatria à Psicanálise - Obras Escolhidas. Rio de Janeiro: Imago.

Winnicott, D. W. (2000). Objetos Transicionais e Fenômenos Transicionais (1951). In Da pediatria à Psicanálise - Obras Escolhidas. Rio de Janeiro: Imago.

Winnicott, D. W. (2000). A Mente e sua Relação com o Psicossoma (1949). In Da pediatria à Psicanálise Obras Escolhidas. Rio de Janeiro: Imago.

Winnicott, D. W. (2000). Retraimento e Regressão (1954). In Da pediatria à Psicanálise - Obras Escolhidas. Rio de Janeiro: Imago.

Winnicott, D. W. (2000). A Posição Depressiva no Desenvolvimento Emocional Normal (1954). In Da pediatria à Psicanálise - Obras Escolhidas. Rio de Janeiro: Imago.
Winnicott, D. W. (2000). Aspectos Clínicos e Metapsicológico da Regressão no Contexto Psicanalítico (1954). In Da pediatria à Psicanálise - Obras Escolhidas. Rio de Janeiro: Imago.

Winnicott, D. W. (2000). Formas Clínicas da Transferência (1955). In Da pediatria à Psicanálise - Obras Escolhidas. Rio de Janeiro: Imago.

Winnicott, D. W. (2000). A Preocupação Materna Primária (1956). In Da pediatria à Psicanálise - Obras Escolhidas. Rio de Janeiro: Imago.

Winnicott, D. W. (2000). A Tendência Anti-Social (1956). In Da pediatria à Psicanálise - Obras Escolhidas. Rio de Janeiro: Imago.

Winnicott, D. W. (2000). Pediatria e Neurose Infantil (1956). In Da pediatria à Psicanálise - Obras Escolhidas. Rio de Janeiro: Imago.

\section{RESUMO}

O trabalho entremeia o relato de um atendimento de uma paciente limítrofe com uma discussão sobre a natureza da psicose e a transformação que causa na técnica psicanalítica. Especial atenção é dada à contribuição winnicotiana ao atendimento de pacientes como este.

Palavras-chave: Pacientes limítrofes, psicose, técnica psicanalítica, Winnicott.

\section{ABSTRACT}

The article intersperses a report of a treatment of borderline patient with a discussion of the nature of psychosis and the transformation it causes in the psychoanalytical technique. A special attention it is given to the Winnicott contribution to the treatment of patients like this.

Key words: Borderline patients, psychosis, psychoanalytical technique, Winnicott. 